2018 Global Marketing Conference at Tokyo Proceedings: 239-240 (July 2018) https://doi.org/10.15444/GMC2018.02.10.01

\title{
ANALYSING CUSTOMER ENGAGEMENT ON SOCIAL NETWORK PLATFORMS DEVOTED TO TOURISM AND HOSPITALITY
}

\author{
Ricardo Godinho Bilro, Instituto Universitário de Lisboa (ISCTE-IUL) and Business \\ Research Unit (BRU/UNIDE), Portugal ${ }^{1}$ \\ Sandra Maria Correia Loureiro, Instituto Universitário de Lisboa (ISCTE-IUL) and \\ Business Research Unit (BRU/UNIDE), Portugal ${ }^{2}$ \\ João Guerreiro, Instituto Universitário de Lisboa (ISCTE-IUL) and Business Research \\ Unit (BRU/UNIDE), Portugal ${ }^{3}$
}

\begin{abstract}
Customers' opinions on social network platforms are known to influence peer behaviour (Bai, 2011; Eirinaki, Pisal, \& Singh, 2012). Customers are also known to be more engaged in sharing their experiences by writing online reviews and recommendations that may be useful to others (Cantallops \& Salvi, 2014; Tang \& Guo, 2015; Xu \& Li, 2016). Actually, user-generated content (UGC) on social network platforms has emerged as an important source for understanding and managing consumers' expectations, particularly using automated and semi-automated knowledge extraction techniques from text such as text mining and sentiment analysis (Zhang, Zeng, Li, Wang, \& Zuo, 2009).

This research analyses dimensions of online customer engagement and associated concepts in customers' reviews through (i) a global sentiment analysis using positive, neutral and negative sentiments and (ii) a topic-sentiment analysis to capture latent topics in online reviews. Furthermore, it examines what influences customers to contribute their online reviews, beyond the features of each focal company or brand.
\end{abstract}

The research methodology is based on a text mining approach, using the MeaningCloud tool. The study focuses on Yelp.com reviews and includes a random sample of 15,000 unique reviews of restaurants, hotels and nightlife entertainment in eleven cities in the USA. An innovative customer engagement dictionary is created, based on previously validated scales using known dimensions of engagement, experience, emotions and brand advocacy, and extended using WordNet 2.1 lexical database.

The research findings reveal a high impact of the engagement cognitive processing dimension and hedonic experience on customers' review endeavour. The study results further indicate that customers seem to be more engaged in positively advocating a company/brand than the contrary. The findings will help social network managers to reinforce their platforms.

Keywords: customer engagement, user-generated reviews, text-mining methodology

\section{References}

\footnotetext{
${ }^{1}$ bilro.ricardo@gmail.com

2 sandramloureiro@netcabo.pt

3 joao.guerreiro@iscte-iul.pt
} 
Bai, X. (2011). Predicting consumer sentiments from online text. Decision Support Systems, 50(4), 732-742.

Cantallops, A. S., \& Salvi, F. (2014). New consumer behavior: A review of research on eWOM and hotels. International Journal of Hospitality Management, 36, 4151.

Eirinaki, M., Pisal, S., \& Singh, J. (2012). Feature-based opinion mining and ranking. Journal of Computer and System Sciences, 78(4), 1175-1184.

Tang, C., \& Guo, L. (2015). Digging for gold with a simple tool: Validating text mining in studying electronic word-of-mouth (eWOM) communication. Marketing Letters, 26(1), 67-80.

$\mathrm{Xu}, \mathrm{X} .$, \& Li, Y. (2016). The antecedents of customer satisfaction and dissatisfaction toward various types of hotels: A text mining approach. International Journal of Hospitality Management, 55, 57-69.

Zhang, C., Zeng, D., Li, J., Wang, F. Y., \& Zuo, W. (2009). Sentiment analysis of chinese documents: From sentence to document level. Journal of the American Society for Information Science and Technology, 60(12), 2474-2487. 